\title{
Intestinal eosinophils, homeostasis and response to bacterial intrusion
}

\author{
Alessandra Gurtner ${ }^{1} \cdot$ Ignacio Gonzalez-Perez $^{1} \cdot$ Isabelle C. Arnold $^{1}$ (D)
}

Received: 2 March 2021 / Accepted: 3 April 2021 / Published online: 30 April 2021

(C) The Author(s) 2021

\begin{abstract}
Eosinophils are traditionally considered as end-stage effector cells involved in the pathogenesis of Th2 immune-mediated disorders as well as in the protection against parasite infection. However, this restricted view has recently been challenged by a series of studies revealing the highly plastic nature of these cells and implication in various homeostatic processes. Large numbers of eosinophils reside in the lamina propria of the gastrointestinal tract, at the front line of host defence, where they contribute to maintain the intestinal epithelial barrier function in the face of inflammation-associated epithelial cell damage. Eosinophils confer active protection against bacterial pathogens capable of penetrating the mucosal barrier through the release of cytotoxic compounds and the generation of extracellular DNA traps. Eosinophils also integrate tissue-specific cytokine signals such as IFN- $\gamma$, which synergise with bacterial recognition pathways to enforce different context-dependent functional responses, thereby ensuring a rapid adaptation to the ever-changing intestinal environment. The ability of eosinophils to regulate local immune responses and respond to microbial stimuli further supports the pivotal role of these cells in the maintenance of tissue homeostasis at the intestinal interface.
\end{abstract}

Keywords Eosinophils $\cdot$ Intestinal homeostasis $\cdot$ Bacterial infections $\cdot$ IFN-gamma $\cdot$ Protective immunity $\cdot$ Extracellular DNA traps $\cdot$ Microbiota $\cdot$ IBDs

\section{Introduction}

Eosinophils arise in the bone marrow from GATA-1-binding factor 1 (GATA-1) positive granulocyte-monocyte progenitors and develop to maturity in response to the cytokines GM-CSF, IL-3 and IL-5. Eosinophils are then released into the peripheral blood as terminally differentiated cells and rapidly migrate to their target tissues. While their half-life in the circulation is relatively short (estimated between 3 and $24 \mathrm{~h}$ ) $[1,2]$, the survival of eosinophils upon migration into peripheral tissues is largely expanded, with turnover rates depending on distinct expression of the common $\gamma$-chain receptor in their target tissues [3]. Eosinophil chemotaxis is mainly driven by the binding of the chemokine eotaxin-1 (CCL11) to its CCR3

This article is a contribution to the Special issue on: Eosinophils - Guest Editor: Hans-Uwe Simon

Isabelle C. Arnold

arnold@immunology.uzh.ch

1 Institute of Experimental Immunology, University of Zürich, Winterthurerstr. 190, 8057 Zurich, Switzerland receptor, with CCL11 produced primarily by cells of stromal origin such as fibroblasts, smooth muscle cells and endothelial cells, but also by epithelial cells [4].

Small numbers of tissue resident eosinophils are found in multiple tissues under steady-state conditions, including the thymus, lung, uterus, mammary gland, adipose tissue and gastrointestinal (GI) tract. Interestingly, eosinophil numbers in the GI tract are substantially higher than in other tissues, accounting for 20-30\% of the total intestinal leukocytes [5]. In addition to the pool of eosinophils present under steady-state conditions, eosinophils can further be recruited to sites of tissue damage in response to injury or exposure to allergen or pathogens, where they exert potent inflammatory effects through the release of cytokines, lipid mediators and cytotoxic granule proteins in a process known as "degranulation". Eosinophil granules typically comprise eosinophil peroxidase (EPX), eosinophil cationic protein (ECP), major basic protein (MBP) and eosinophil-derived neurotoxin (EDN). The tight regulation of eosinophil effector functions is crucial for the development of beneficial immune responses and the simultaneous avoidance of excessive tissue damage. The abnormal presence of eosinophils in peripheral organs is therefore 
generally associated with disease. Eosinophilia is a major hallmark of allergic asthma in the airways [6, 7] and of allergic skin manifestations such as atopic dermatitis [8], but is also typical of chronic inflammatory conditions of the GI tract such as inflammatory bowel diseases (IBD) and eosinophilassociated gastrointestinal disorders (EGIDs - a family of conditions characterised by inappropriate GI eosinophil accumulation in the context of Th-2-driven immune polarisation) [9-11]. The tissue-damaging consequences of eosinophilia at these sites have been attributed to several factors released by activated eosinophils as they degranulate.

In the GI tract, eosinophils are scattered throughout the lamina propria of the stomach, small intestine, cecum and colon but are absent from the oesophagus. Eosinophils are recruited to the GI tract already during fetal life, before the establishment of the intestinal microflora [2]. The strategic location of intestinal eosinophils close to the mucosal interface and their expression of various Toll-like receptors (TLRs) at the cell surface suggests that they can sense and respond to microbial stimulation. Recent evidences show that eosinophils not only contribute to shape the composition of the intestinal microbiota - directly or indirectly via the modulation of mucosal immune responses - but also respond to bacterial components or bacterially derived metabolites. In this review, we concisely summarise the current understanding of eosinophil contribution to intestinal homeostasis and highlight recent literature investigating their ability to recognise and eliminate bacterial pathogens in the GI tract. We further discuss studies exploring interactions between eosinophils and the intestinal microbiota. As eosinophil contribution to the pathogenesis of Th2-oriented conditions such as asthma, allergy or infection with parasites has already been reviewed extensively [12-14], we focus here on evidence of their priming by the cytokine IFN- $\gamma$ and potential implication in Th1 polarised immune settings such as following bacterial infections and bacterially driven inflammation.

\section{Eosinophil immunoregulatory function in intestinal homeostasis}

The intestinal lamina propria is home to a dense and highly specialised mucosal immune system, comprising multiple $\mathrm{T}$, $\mathrm{B}$, innate lymphoid and myeloid cell subsets that act in concert with epithelial and stromal cell populations to mount effector immune responses against pathogens while avoiding deleterious responses to commensals. This dynamic crosstalk ensures the coexistence of the immune system with the microbiota in a mutually beneficial relationship, also known as "homeostasis".

Eosinophils contribute to the maintenance of intestinal homeostasis in several ways. They preserve the epithelial barrier integrity by enhancing intestinal mucus secretion and eosinophil-deficient mice display decreased mucusexpressing goblet cells in the small intestine [15]. Eosinophils also support the maintenance of IgA-producing plasma B cells, which in turn promote the development of Peyer's patches and modulate the composition of the intestinal microbiota $[15,16]$. In addition, there is growing evidence on the role of eosinophils in regulating local immune responses, especially of $\mathrm{T}$ cells. Indeed, eosinophils down-regulated Th17 cells in the small intestine by secreting IL-1 receptor antagonist (IL-1R $\alpha$ ), a natural inhibitor of IL-1 $\beta$ [16]. Similarly, the frequencies of mucosal Th1, but not Th2 cells, were strongly increased in the GI tract of mice depleted of eosinophils in a microbiota-dependent manner [17] (Fig. 1). GI eosinophils were also reported to suppress Th2 responses in Peyer's patches during intestinal infection by nematodes [18]. In contrast, enteric eosinophils promoted the initiation of Th2 immunity by controlling the activation and migration of $\mathrm{CD} 103^{+}$dendritic cells to draining lymph nodes in response to local EPX release in a model of food allergy [19]. These studies indicate that eosinophils might restrict inappropriate $\mathrm{T}$ cell responses to promote mucosal homeostasis, but that their function might be highly context dependent.

Eosinophil can also influence $\mathrm{T}$ cell responses indirectly, by promoting the differentiation of regulatory $\mathrm{T}$ cells (Tregs). Indeed, the analysis of eosinophil-deficient mice revealed a notable reduction in the frequencies of intestinal Foxp $3^{+}$ Tregs correlating with decreased TGF- $\beta$ activating factors MMP3 and MMP9 [20]. Similarly, intestinal eosinophils but not peripheral blood eosinophils induced the differentiation of naïve $\mathrm{T}$ cells into Foxp $3^{+}$Tregs cells in vitro through the release of TGF- $\beta 1$ and retinoic acid [21]. Recent reports have described the existence of a unique microbiota-induced Treg subset expressing the nuclear hormone receptor ROR $\gamma \mathrm{t}$, which controls intestinal inflammation [22-24]. Whether intestinal eosinophils also contribute to the differentiation of this specialised subset associated with enhanced suppressive functions still remains to be determined the effects of eosinophils on the maintenance of intestinal homeostasis.

\section{Pathways involved in eosinophil activation during bacterial infections}

\section{Bacterial recognition pathways driving eosinophil activation}

The mucosal immune system recognises microbial components and metabolites through several families of innate immune receptors, resulting in the production of cytokines, antimicrobial proteins and immunoglobulins $(\operatorname{IgA})$ that maintain intestinal barrier integrity. Eosinophils are well equipped to sense and respond to bacterial stimulation. They express a vast varry of pattern-recognition receptors (PRRs) capable of 


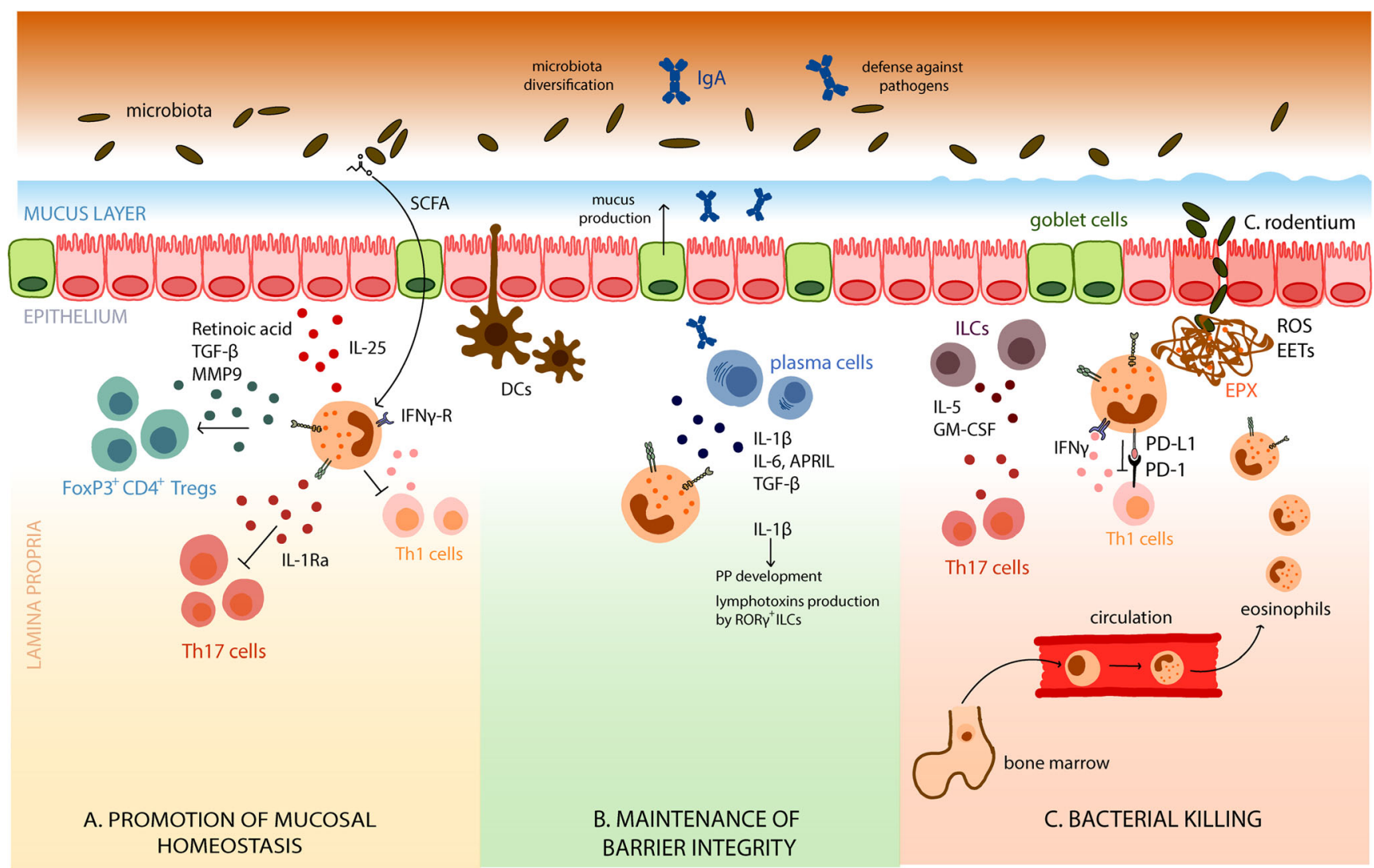

Fig. 1 Roles of eosinophils in intestinal homeostasis and host protective immunity. The gastrointestinal tract is home to a large population of resident eosinophils. a Under physiological conditions, eosinophils integrate tissue-derived signals and bacterial metabolites to promote mucosal homeostasis. They restrict inappropriate Th1 responses in response to microbiota-derived signals and inhibit Th17 cell by secreting IL-1R $\alpha$. Eosinophils also promote the differentiation of regulatory T cells via the release of TGF- $\beta$, MMP9 and retinoic acid. b Eosinophils maintain epithelial barrier integrity by enhancing intestinal mucus secretion and supporting IgA-producing plasma B cells through

recognising specific evolutionarily conserved microbial components called pathogen-associated molecular patterns (PAMPs), as well as damage-associated molecular patterns (DAMPs). PRR engagement on eosinophils activates intracellular signalling cascades leading to a broad range of responses, including the release of pro-inflammatory cytokines, chemokines, cytotoxic granule proteins, leukotrienes and reactive oxygen species, the upregulation of adhesion molecules increasing cellular trafficking as well as enhanced survival. Eosinophils express several families of PRR, including tolllike receptors (TLRs), RIG-I-like receptors (RLRs), nucleotide-binding oligomerisation domain-like (NOD-like) receptors as well as the receptor for advanced glycation end products (RAGE) [25]. An overview of the patternrecognition receptors expressed on eosinophils are reviewed by Kvarnhammar et al. [25].

TLRs recognise PAMPs in different cellular compartments. TLR1, $-2,-4,-5,-6$ and -10 are positioned on the cell surface and primarily detect bacterial proteins, lipoproteins the production of cytokines such as IL- $1 \beta$, TGF- $\beta$ and IL- 6 , leading to the diversification of the microbiota. Eosinophil-derived IL-1 $\beta$ also promote the development of Peyer's patches and lymphotoxins production by ROR $\gamma^{+}$ILCs. $\mathbf{c}$ In response to bacterial pathogens such as $C$. rodentium breaching the epithelial barrier, eosinophils are further recruited from the bone marrow to sites of tissue damage, where they are conditioned by IFN- $\gamma$ to facilitate bacterial killing through the release of extracellular DNA traps (EETs) and associated cytotoxic granule proteins. Concomitantly, eosinophils also downmodulate Th1 responses via the expression of PD-L1

and polysaccharides. In contrast, TLR3, $-7,-8$ and -9 are located in endosomes, where they detect mostly viral nucleic acids. All TLRs except TLR8 have been detected in eosinophils at the mRNA or protein level. Peripheral blood eosinophils were reported to prominently express TLR7 [25], which recognises single-stranded RNA. While TLR7 signalling in eosinophils might contribute to host protection against viral pathogens, it remains to be determined whether it might also participate in the recognition of the viral component of the gut microbiome. The stimulation of human eosinophils with TLR2, TLR5 and TLR7 agonists led to the upregulation of intercellular adhesion molecule-1 (ICAM1) and of surface CD18 expression, together with the release of IL1 $\beta$, IL- 6 , IL-8, CXCL1 and superoxides. These effects were mediated by the combined action of ERK kinase, PI3K kinase and NF-KB pathways [26]. In contrast, only the TLR2 agonist peptidoglycan (PGN) could induce eosinophil degranulation and ECP release [26]. In a study of Driss et al., both the live form of $M$. bovis bacillus Calmette-Guérin (BCG) and 
purified lipomannan promoted the synthesis of reactive oxygen species, EPX, ECP, TNF- $\alpha$ and $\alpha$-defensins in a TLR2/Myd88-dependent manner [27]. Eosinophils further responded to bacterial lipopolysaccharide (LPS) stimulation, a TLR4 agonist, by enhanced survival and secretion of the cytokines GM-CSF, TNF- $\alpha$ and IL-8 [28] as well as by the release of ECP in a CD14-dependent manner [29]. However, the function of PRRs has mostly been studied in vitro, in isolated single cell systems, which neither take into account the tissue-specific characteristics of eosinophils nor recapitulate the local cytokine network. Indeed, it is likely that eosinophil response to selected bacterial triggers synergises with activating cytokine signals in a given tissue to increase TLR expression and signal transduction.

\section{Eosinophil priming through the Th1 cytokine IFN- $\gamma$}

Among the cytokines priming eosinophil activation within the GI tract, IFN- $\gamma$ might play an important role. IFN- $\gamma$ is a pleiotropic cytokine produced predominantly by innate lymphoid cells (ILCs), natural killer (NK) cells, T-helper 1 (Th1) CD4 ${ }^{+}$ $\mathrm{T}$ cells and cytotoxic $\mathrm{CD} 8^{+} \mathrm{T}$ cells. IFN- $\gamma$ signalling through the IFN- $\gamma$ receptor (IFN- $\gamma$ R) activates the Janus kinase (JAK)-signal transducer and activator of transcription 1 (STAT1) pathway to induce the expression of classical interferon-stimulated genes that have key immune effector functions, such as host defence against bacterial pathogens, modulation of immune and inflammatory responses as well as tumour immunosurveillance [30].

During microbial infection or tissue damage, an early burst of IFN- $\gamma$ is produced by innate-like cells in response to the cytokines IL-12, IL-18 or following the activation of PRRs. This is followed by high and prolonged levels of IFN- $\gamma$ produced by Th1 or $\mathrm{CD}^{+} \mathrm{T}$ cells upon TCR engagement in response to microbial peptide recognition [30]. IFN- $\gamma$ is well known to regulate the function of multiple immune and non-immune cell types, including helper $(\mathrm{Th})$ and follicular helper (Tfh) $\mathrm{T}$ cells, regulatory $\mathrm{T}$ (Treg) cells, B cells, innate-like lymphocytes, endothelial cells, stromal cells, adipocytes and neural cells [30]. IFN- $\gamma$ is also a potent activator of different myeloid cells. In macrophages, IFN- $\gamma$ mediates the polarisation to an 'M1-like' state [31], which results in their hyper-responsiveness to inflammatory stimuli and enhances their pro-inflammatory activity while promoting resistance to tolerogenic or anti-inflammatory factors [30]. IFN- $\gamma$ further induces the local differentiation of monocytes into dendritic cells and macrophages at sites of infection [32]. In neutrophils, priming by IFN- $\gamma$ increases oxidative metabolism, surface receptor expression and degranulation and strongly enhances their ability to kill pathogens [33].

By contrast, the effect of IFN- $\gamma$ on eosinophil function is less well understood. IFN- $\gamma$ was reported to promote the degranulation of human eosinophils and to enhance their production of superoxide anions following GM-CSF or IL-5 priming [34]. Further studies highlighted the role of IFN- $\gamma$ in eosinophil primary granule mobilisation and piecemeal degranulation, a vesicle-dependent process allowing the selective release of part of their granule-stored contents. Indeed, IFN- $\gamma$ induced the mobilisation of CD63 (a component of the late endosomal and lysosomal membranes also present in "secretory lysosomes," [35]) to eosinophil peripheral membranes, together with the selective release of the chemokine CCL5 $[36,37]$. The release of extracellular cell-free granules that retain their content of preformed cytokines and cationic proteins is typically observed during cytolysis, a nonapoptotic form of cell death [38] and is well documented in several human pathologies [39-41]. Interestingly, the extracellular granules of human, but not of mouse eosinophils, express the IFN- $\gamma$ receptor $\alpha$-chain (IFNGR1) on their membrane and remain ligand responsive, with the ability to differentially secrete their cationic proteins or cytokine contents [42, 43]. Thus, binding of IFN- $\gamma$ to its receptor might continue to induce the local release of eosinophil granule proteins even in the absence of live eosinophils, thereby ensuring a longlasting effect. Besides its effect on granule mobilisation, IFN- $\gamma$ also supports eosinophil antimicrobial functions. The stimulation of mouse eosinophils with IFN- $\gamma$ led to the killing of the parasite L. amazonensis in vitro in a reactive oxygendependent manner, but independent of their degranulation [44]. In addition, the priming of human eosinophils with IL5 or IFN- $\gamma$ is required for the release of eosinophil DNA traps in response to LPS stimulation [45].

In the GI tract, basal levels of IFN- $\gamma$ are expressed in response to specific commensal bacteria [46] and strongly increases during infection or inflammation. Our group has reported a key role for IFN- $\gamma$ in the regulation of eosinophils in settings of acute and chronic bacterial infection [17]. We found that eosinophils are cell-intrinsically conditioned by IFN- $\gamma$ levels in their residential tissues to promote homeostasis and restrict immunopathology by locally suppressing Th1 responses in an experimental model of H. pylori infection. Mice lacking the IFN- $\gamma \mathrm{R}$ specifically in the eosinophil lineage mirrored the phenotype of eosinophil-deficient PHIL mice and exhibited higher frequencies of mucosal Th1 cells. The regulatory capacity of eosinophils toward Th1 cells depended at least in part on their PD-L1 expression but was independent of degranulation. Eosinophils isolated from infected tissues further exhibited a strong IFN- $\gamma$-associated genes signature characterised by the expression of Pdl1, Cxcl10, Stat1 and Ccl5. The upregulation of these transcripts could be recapitulated in vitro upon stimulation of IFN- $\gamma$-primed eosinophils with live $H$. pylori and depended on the synergistic effect of both, $H$. pylori and IFN- $\gamma$ stimulation, as neither signal alone was sufficient to drive differential gene expression [17]. Similarly, the transcriptional and proteomic analysis of colonic intra-tumoral eosinophils in a model of colitis-induced cancer revealed a strong IFN- $\gamma$-linked signature, indicating a key 
role for IFN- $\gamma$ in activating eosinophils in experimental colorectal cancer [47]. It is interesting to note that in settings of chronic intestinal inflammation, IFN- $\gamma$ producing $\mathrm{T}$ cells accumulate not only in the colon of mice, but also in the bone marrow [48]. There, IFN- $\gamma$ increases the proliferation of longterm hematopoietic stem cell progenitors (LT-HSC) resulting in the enhanced production of downstream granulocytemonocyte progenitors (GMPs), which also give rise to eosinophils [48, 49]. While this feed-forward mechanism may contribute to increase the eosinophil output observed during intestinal inflammation [50], it would be interesting to assess whether eosinophils are to a certain extent pre-activated by IFN- $\gamma$ before reaching their target organs and whether this conditioning might impact their functional properties. The potential effects of IFN- $\gamma$ signalling on eosinophil functions are summarised in Fig. 2.

\section{Eosinophils in host protective immunity against bacterial pathogens}

Eosinophils have traditionally been associated with protection against parasitic helminth infections. However, emerging evidences show that eosinophils are also involved in the recognition and elimination of other pathogens such as viruses, fungi and bacteria. Eosinophil bactericidal activity might be particularly important at mucosal interfaces and in environments with high bacterial stimulation such as in the GI tract. In situations where the epithelial barrier integrity is compromised-such as during infection or chronic inflammation - the release of cytotoxic granules in association with EETs might provide a second physical barrier aimed at limiting bacterial invasion, but might also contribute to the pathogenesis of chronic inflammatory conditions such as IBD [45].

\section{Eosinophils in inflammatory bowel diseases (IBDs)}

IBDs are chronic relapsing disorders affecting the gastrointestinal tract and associated with high morbidity. The two main forms of IBDs, Crohn's disease and ulcerative colitis, are characterised by intestinal inflammation and epithelial injury. The precise aetiology of IBDs is still unclear, but chronic inflammation seems to arise from an abnormal immune response against the microorganisms of the intestinal flora in genetically susceptible individuals, resulting in the breakdown of intestinal homeostasis. IBD patients therefore often present signs of microbial imbalance, intestinal barrier dysfunction and dysregulation of the intestinal mucosal immune system. As opposed to primary EGIDs, which feature a predominant eosinophilic infiltrate, IBDs are characterised by a heterogeneous infiltration of inflammatory leukocytes, together with a

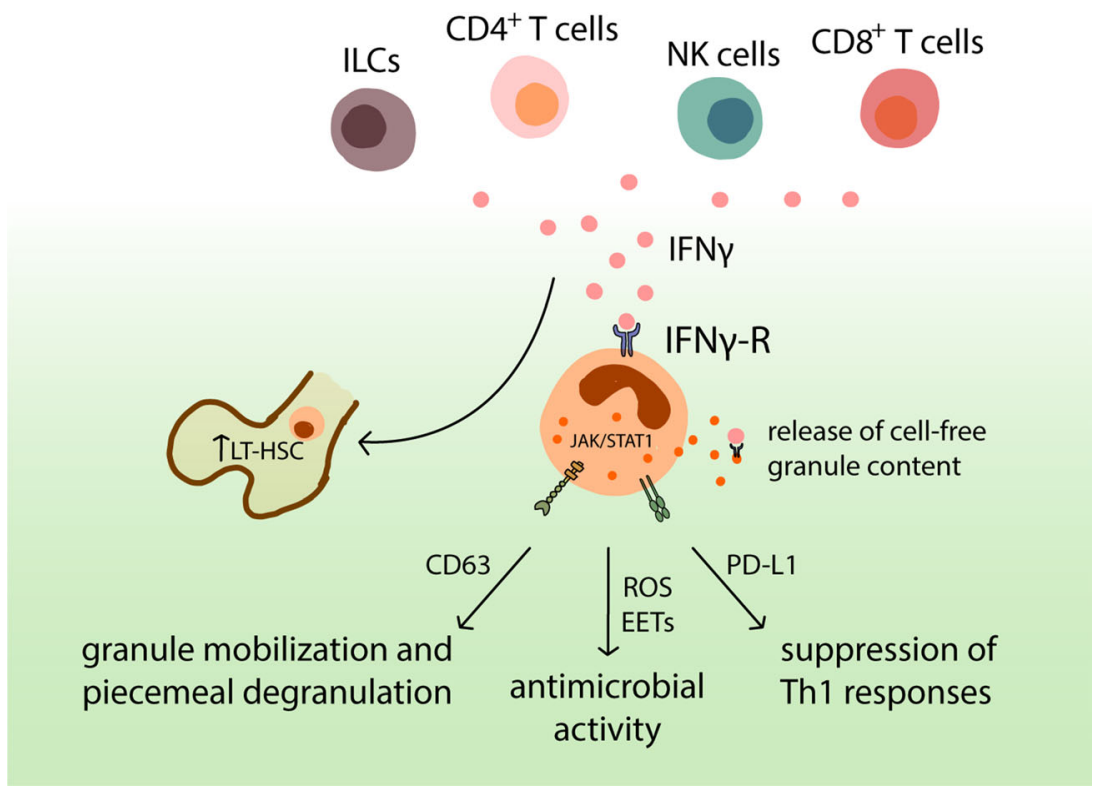

Fig. 2 Eosinophil regulation by IFN- $\gamma$. Under homeostatic conditions, basal levels of IFN- $\gamma$ are produced by innate lymphoid cells (ILCs), natural killer (NK) cells, T-helper 1 (Th1) $\mathrm{CD}^{+}{ }^{+} \mathrm{T}$ cells and cytotoxic $\mathrm{CD} 8^{+} \mathrm{T}$ cells. IFN- $\gamma$ induces mobilisation of CD63 to eosinophil peripheral membranes, followed by the piecemeal release of chemokines and granule proteins. Upon microbial infection or tissue damage, high and sustained expression of IFN- $\gamma$ induces ROSdependent antimicrobial activities and the release of EETs. During both acute and chronic bacterial infection, eosinophils prevent excessive inflammation by regulating local Th1 responses through the upregulation of PD-L1 in response to IFN- $\gamma$ signalling. Besides its direct action on eosinophils, IFN- $\gamma$ further promotes bone marrow eosinopoiesis by supporting the proliferation of long-term hematopoietic stem cell progenitors (LT-HSC). IFN- $\gamma$ might also bind to the IFN- $\gamma \mathrm{R}$ expressed at the surface of intact extracellular eosinophil granules, leading to the release of granular content even in the absence of live eosinophils 
marked increase in eosinophil numbers resulting from enhanced production of eotaxin 1 in the lamina propria by colonocytes, macrophages or B cells [51]. Strong evidence suggests that eosinophils play a cardinal role in the pathogenesis of IBDs by promoting tissue damage through excessive degranulation, likely in an attempt to protect the host from pathogen incursion [52]. Intestinal eosinophil densities or faecal granule protein levels directly correlate with disease severity [53], while eosinophil degranulation at sites of active mucosal inflammation is commonly reported [54, 55]. Interestingly, eosinophils seem to a certain extent preactivated in the circulation of IBD patients, suggesting that mediators such as inflammatory cytokines and chemoattractants might prime their activation systemically [56]. Despite circumstantial evidence for a pathogenic role of eosinophils in IBD, the observation that high levels of activated eosinophils persisted in the lamina propria of UC patients in disease remission [57] suggests that tissue eosinophilia cannot be solely linked to eosinophil pro-inflammatory activities and might be highly context-dependent. The difficulty of attributing a definitive functional contribution of eosinophils to the pathogenesis of IBD is further illustrated in experimental models of intestinal inflammation, where eosinophil deficiency resulted in either ameliorated or worsened inflammation depending on the model used $[50,58,59]$.

\section{Antibacterial properties of eosinophil granule proteins}

The importance of eosinophils in host protection against bacterial pathogens is illustrated by Linch et al. describing the protective effect of eosinophilia in IL-5 transgenically engineered mice against $P$. aeruginosa [60]. While eosinophil-deficient mice were highly susceptible to peritonitis following $P$. aeruginosa infection and exhibited impaired bacterial clearance, the presence of eosinophilia or the adoptive transfer of eosinophil granule extracts reduced the bacterial load in vivo [60]. The antibacterial properties of eosinophil granule proteins are well documented for ECP, MBP, and EPX and are reviewed in Gigon et al. [61].

$\mathrm{ECP}$ is uniquely expressed in eosinophils and exerts potent antibacterial properties against both Gram-negative and Gram-positive strains independently of its ribonuclease activity [62]. Elevated levels of serum ECP are often found in patients with bacterial infections, leading to the conclusion that eosinophil activation in this setting results in the preferential mobilisation of ECP [63, 64]. The bactericidal effects of ECP can be related to its membrane disruption capacity [65-67] and ability to bind the bacteria-wall components LPS and PGN with high affinity, leading to membrane depolarisation [68]. ECP also induces bacterial aggregation and forms amyloid aggregates in vitro [68, 69], potentially enhancing pathogen agglutination and killing at the infection foci. Similarly, MBP-1 exhibits non-selective cytotoxicity toward bacteria by binding to and permeabilising bacterial membranes [67, 70]. Upon release, MBP-1 aggregates and forms amyloids that facilitate antimicrobial activity. Interestingly, large MBP amyloid plaques present in the tissues of eosinophilic patients are characterised by decreased cytotoxicity and were proposed to result from a feedback mechanism aimed at limiting tissue damage under pathological conditions, while providing a scaffold for the recruitment of innate immune cells [71]. Indeed, the stimulation of human eosinophils with MBP leads to further degranulation and release of IL-8 [72], a pro-inflammatory cytokine with potent chemoattractant properties for innate immune cells. EPX is a cationic haloperoxidase that shares $70 \%$ amino acid homology with the better characterised neutrophil myeloperoxidase [73]. EPX catalyzes the oxidation of halide and pseudohalides ions present in the plasma together with hydrogen peroxide to form highly cytotoxic hypohalous acids involved in bacterial killing [10]. EPX interacts with the superoxide generated by the NADPH oxidase to provide the bactericidal activity of eosinophils $[74,75]$.

\section{Eosinophil-derived extracellular DNA traps}

The elimination of bacterial pathogens mainly occurs extracellularly through the release of eosinophil granule proteins at high local concentration, which are toxic to both pathogens and neighbouring cells. Interestingly, granule proteins can also be found attached to DNA released from activated eosinophils. These so-called extracellular traps (EETs) form a localised scaffold that captures both granule proteins and bacteria, thereby ensuring the targeted killing of pathogens while limiting cytotoxic damages to the surrounding tissues. While the deposition of extracellular DNA by eosinophils contributes to the innate host defence machinery, it also likely plays an important role in the development of certain pathologies, particularly in settings of chronic, unresolved inflammation. Evidence of eosinophil-derived extracellular DNA depositions are observed in multiple human pathologies, including Crohn's disease [45], allergic asthma [76], atopic dermatitis [77] and eosinophilic esophagitis [78], as well as following bacterial infections $[45,79]$

The release of EETs can be initiated by several mechanisms, including TLR-, cytokine-, chemokine- and adhesion receptormediated signal transduction pathways [80]. The mechanism of EET formation and origin of the released DNA are still a matter of debate and are discussed elsewhere [81]. Yousefi et al. first demonstrated the catapult like release of mitochondrial DNA in response to bacteria such as $E$. coli, which led to rapid bacterial killing in a phagocytosis-independent manner [45]. The release of EETs could further be recapitulated in vitro by stimulating human eosinophils with LPS, complement receptor 5a or eotaxin following IL-5 and/or IFN- $\gamma$ priming. This process 
depended on reactive oxygen species and was independent of cell death or apoptosis [45]. Degranulation and EETs formation seem to rely on different molecular pathways, as the release of eosinophil granule proteins was reported to precede the release of DNA, implying that their association takes place in the extracellular space [82].

The relevance of EETs in eosinophil bactericidal activities was further demonstrated in vivo. In a model of post-caecal ligation and puncture, IL-5 transgenic but not wild-type mice displayed substantial deposition of extracellular DNA indicative of EETs, which protected mice against microbial sepsis [45]. In a model of acute colitis induced by the pathogen $C$. rodentium, eosinophils were rapidly recruited to the colonic lamina propria upon bacterial challenge, where they degranulated and released EETs associated with EPX (Fig. 1) [17]. In the absence of eosinophils, mice displayed impaired bacterial clearance and increased susceptibility to the pathogen, as evidenced by stronger Th1/Th17 responses and immunopathology. C. rodentium was further highly
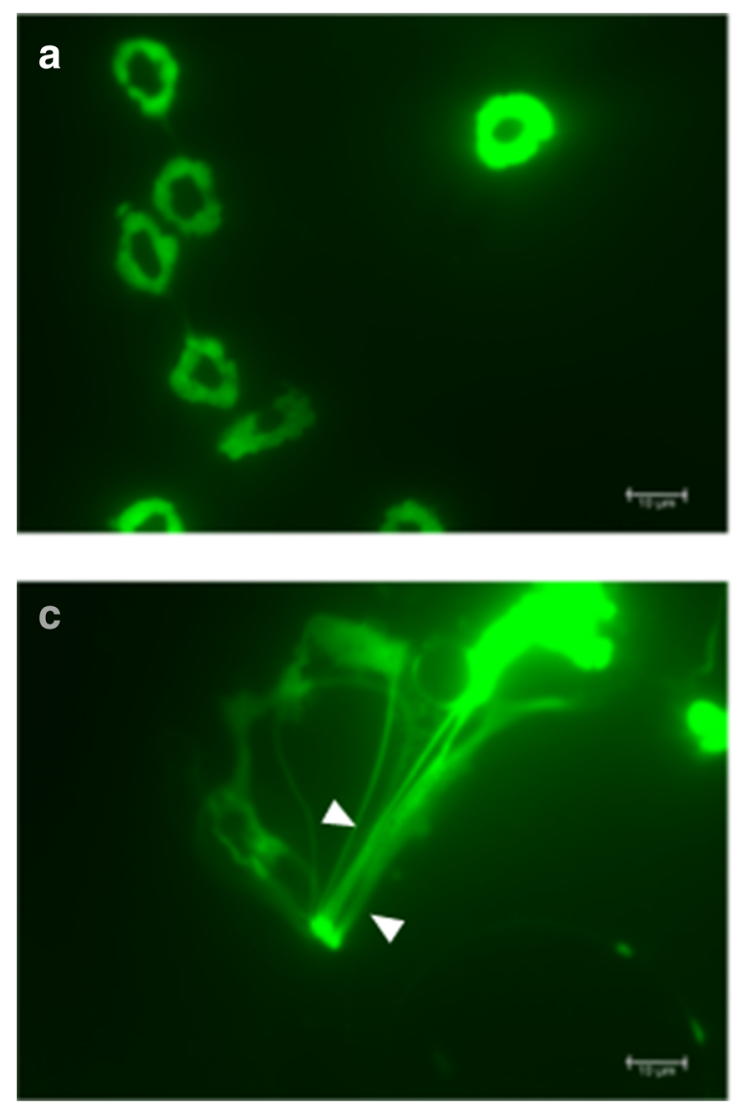

Fig. 3 Selected bacterial species promote eosinophil DNA extracellular trap formation (EETs). a-d Eosinophils were isolated from the spleens of IL5-tg mice and sorted by flow cytometry. Eosinophils were then infected with live Helicobacter hepaticus (b), Citrobacter rodentium (c), Salmonella typhimurium MCI (d) for $15 \mathrm{~min}$ at $37{ }^{\circ} \mathrm{C}$ or were left untreated (a). Cells further received $5 \mu \mathrm{M} /$ well of the nucleic acid stain Sytox green (Invitrogen) 5 minutes after infection, and were visualised for susceptible to killing by activated eosinophils in vitro and bacterial viability coincided with the release of EPX and the formation of EETs [17]. Interestingly, the triggering of EETs leading to bacterial killing seems to be highly dependent on the nature of the bacterial stimuli, as only selected bacterial species-such as C. rodentium and S. Typhimurium but not $H$. hepaticus or H. pylori-are capable of provoking EETs in vitro (Fig. 3). In addition, the induction of lytic cell death and extracellular DNA release by $S$. aureus depended on the expression of its Hla virulence factor [83]. It is thus tempting to speculate that the inactivation of specific bacterial virulence factors, a strategy commonly employed by pathobionts such as $H$. pylori to escape immune recognition [84], might also contribute to avoid eosinophil-mediated killing. Future studies addressing the mechanisms through which selective bacterial species or virulence factors are recognised by eosinophils and lead to distinct functional responses would thus help to better understand the role of eosinophils in bacterial infections and bacterially driven pathologies.
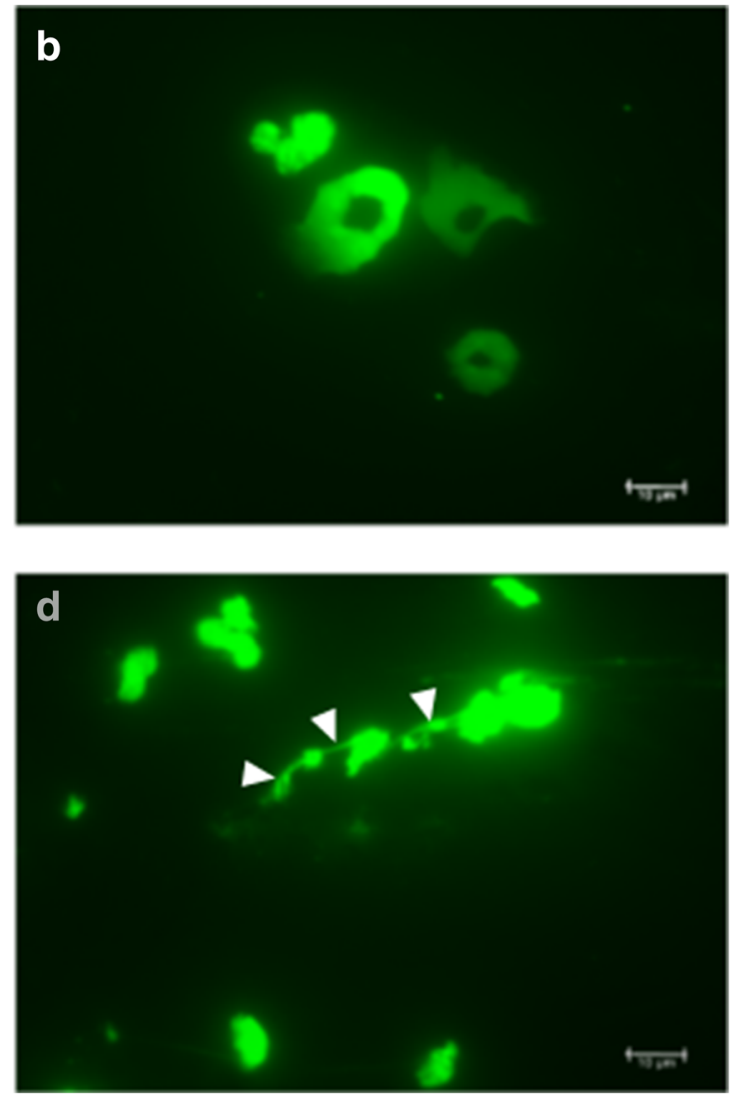

extracellular trap formation on a Leica DM6 B microscope. White arrows point toward EETs. The formation of EETs was clearly visible in C. rodentium infected eosinophils, while less marked DNA filaments and nuclear disintegration was observed following $S$. typhimurium infection. In contrast, EETs formation was not observed in response to $H$. hepaticus infection or in uninfected eosinophils. Scale bar represents $10 \mu \mathrm{m}$ 


\section{Eosinophils and the microbiota}

The GI tract is home to the densest microbial communities known. Bacteria outnumber host cells by a factor of 10 and exist in a highly adapted and mutualistic relationship with the host, contributing to nutrition, immune system development and function, as well as protection from pathogens. Imbalance in the microbiota composition is referred to as "dysbiosis" and is associated with the pathogenesis of both intestinal and extra-intestinal disorders [85]. Dysbiosis is also commonly observed in IBD patients and is characterised by an overall reduced bacterial diversity together with an increased abundance of mucolytic, sulfate reducing and pathogenic bacteria, which contribute to alter mucosal integrity and promote inflammation [86].

Eosinophils are located in the GI lamina propriaseparated from our microbial residents by just a single layer of epithelial cells. While several studies have reported an important role for eosinophils in maintaining a homeostatic composition of the intestinal microbiota, much less is known about how microbiota-derived factors and metabolites might regulate local eosinophil functions.

\section{Modulation of the intestinal microbiota by eosinophils}

Immunoglobulin A $(\operatorname{Ig} \mathrm{A})$ is the dominant antibody isotype found in mucosal secretions and promotes host-microbiota symbiosis by impacting the composition and density of intestinal bacterial communities. IgA is secreted into the gut lumen, where it binds to and 'coats' specific members of the microbiota. While the functional consequences of IgA binding are still incompletely understood, impaired IgA production is related to decreased overall microbial diversity and shifts in the relative abundances of specific bacterial taxa [87-89]. Chu et al. first reported that eosinophil-deficient mice generated through the deletion of a high-affinity GATA-binding site in the GATA-1 promoter ( $\Delta$ dblGATA-1) $[90]$ have impaired generation and maintenance of IgA plasma cells in the small intestine [20]. In this study, eosinophils directly regulated GI IgA production through their expression of IL-6, APRIL and TGF- $\beta$ via TLR-mediated signalling, resulting in reduced secretory IgA levels, less IgA adherence to faecal bacteria and a reduction of Gram-positive bacteria, possibly Firmicutes [20]. Similarly, Jung et al. described the reduced expression of secretory IgA and bacterial imbalance associated with impaired Peyer's patches development in the absence of eosinophils, but suggested an indirect regulatory mechanism implicating eosinophil-derived IL-1 $\beta$ and lymphotoxins [15]. A schematic depiction of the pathways through which eosinophils support the generation of IgA is represented in Fig. 1. In contrast to these reports, later studies found only modest or no differences in the numbers of IgA-secreting plasma cells in eosinophil deficient mice, proposing that factors such as the genetic background or age of mice might account for these differences [91, 92]. More recently, Beller et al. reported that mucosal IgA production was in fact determined independently of eosinophils by specific members of the intestinal microbiota themselves [93]. The cohousing of eosinophil-deficient mice with their wild-type counterparts prior to analysis led to the equalisation of their microbiota and normalisation of IgA levels, in contrast to non-cohoused animals. By comparing the microbiome of eosinophil-deficient and wild-type mice, bacteria enriched for the genus Anaeroplasma were further identified as major driver of TGF- $\beta$ expression in intestinal $\mathrm{T}$ follicular helper cells leading to IgA class switching and enhancing mucosal IgA levels [93]. Interestingly, the microbial analysis of cohoused $\Delta$ dblGATA- 1 and wild-type littermates revealed that the absence of eosinophils primarily affect the composition of mucus-resident bacterial species in the large and small intestine, with little change in mucosal IgA [92]. These observations implicate that eosinophils might also regulate the microbiota by mechanisms independent of IgA, especially the bacteria most hyperlocal to the gut barrier. The impact of eosinophils on the microbiota composition might be triggered directly through the secretion of anti-bacterial factors or indirectly, by promoting the production of epitheliumderived anti-bacterial peptides or through the regulation of local immune responses. While eosinophils clearly seem to participate in the dynamic modulation of intestinal bacterial communities, the mechanisms behind these activities are likely to extend beyond the action of $\operatorname{Ig} \mathrm{A}$ alone.

\section{Eosinophil response to microbial signals}

Besides their impact on the microbiota composition, eosinophils also respond to microbial stimuli in several ways. While eosinophils can directly encounter specific pathogens capable of dwelling through the dense GI mucosal layer [17], direct contacts between eosinophils and commensal bacteria are less likely to occur under homeostatic conditions due to the strict compartmentalisation of the intestinal microbiota to the mucosal surface. Eosinophils might thus recognise bacterial metabolites or might be conditioned indirectly via microbiotaderived signals acting via the epithelium. Indeed, a crosstalk between eosinophils and intestinal epithelial cells has been proposed to limit $C$. difficile infection in an IL-25dependent manner [94]. Buonomo et al. reported that mice treated with the microbiota-regulated cytokine IL-25 were protected from lethal $C$. difficile infection in an eosinophildependent manner. Mice lacking eosinophils suffered profound epithelial destruction unrelated to the levels of bacterial colonisation, IL-4, mucin or IgA [94]. The results suggest that in response to microbial signals, epithelial-derived IL-25 promotes eosinophil homeostatic function that maintains epithelial barrier integrity. In addition, a recent report indicated that 
eosinophil survival was negatively regulated by the bacterial metabolite butyrate [84]. Butyrate is a short chain fatty acid (SCFA) produced through the microbial fermentation of dietary fibres in the lower intestinal tract and has received much attention recently for its beneficial effects on intestinal homeostasis and anti-inflammatory properties [85]. Patients with IBDs have an altered gut microbial composition and a concurrent reduction in butyrate-producing bacteria [95]. Interestingly, both mouse and human eosinophils express strikingly high levels of the SCFA receptors GPR43 and GPR41 (free fatty acid receptors 2 and 3, respectively) in comparison to other leukocytes [96, 97]. In vitro, butyrate induced eosinophil apoptosis and attenuated their migratory and adhesion capacities. Butyrate further alleviated allergic airway inflammation by limiting eosinophil trafficking in vivo [85]. While the physiological relevance of these observations in the context of intestinal homeostasis still needs to be further explored, it suggests that eosinophil survival and possibly functional polarisation in the lamina propria might be directly controlled by commensal-derived metabolites.

The critical interplay between the microbiota and intestinal eosinophils in shaping homeostatic immune processes is further illustrated in studies using germ-free (GF) mice. In a recent reported, Jiménez-Saiz and co-workers report a significantly higher frequency of eosinophils in the intestines of GF than of specific pathogen free control animals [98]. The intestinal eosinophils of GF mice also exhibited a striking reduction of cytoplasmic granule size and content, further supporting a role for the microbiota in shaping the phenotype and density of local eosinophil populations. Interestingly, GF mice also displayed increased eosinophil frequencies at other mucosal sites such as the lung or the vaginal tract but not in sterile tissues such as spleen or uterus, which could be normalised by microbiota repletion. [98]

While microbiota-derived signals seem to modulate different aspects of eosinophil biology, the precise nature of these signals and whether they might synergise with local cytokine networks to enforce a niche-specific spectrum of activities resulting in distinct functional subsets still needs to be investigated further.

\section{Concluding remarks}

Eosinophils are an integral part of the resident intestinal immune system, conferring protection against invading pathogens while exerting subtle regulatory effects on local immune cells. In addition to their homeostatic functions, eosinophils also promote inflammation and tissue damage through their excessive degranulation in settings of chronic, unresolved inflammation. Despite these evidences, eosinophils are often overlooked. With the development of new experimental models of eosinophil deficiency and tools specifically targeting the eosinophil lineage, the extent of their contribution to tissue homeostasis and protective immunity has slowly begun to be revealed. However, these experimental strategies may underestimate the phenotypic diversity of tissue-resident or disease-associated eosinophils. Further studies relying on modern technologies such as proteomics, single cell sequencing or high-dimensional flow-cytometry might thus help to elucidate the intricate molecular pathways defining eosinophil heterogeneity along the GI tract. The identification of distinct functional subsets might further lay the basis for exploiting new pharmacological strategies to manipulate eosinophil activities in pathologies such as IBD and provide mechanistic insights that may be applicable to other eosinophil-mediated disease contexts.

Funding Open Access funding provided by Universität Zürich. This work was supported by a Swiss National Science Foundation Project Grant 310030182744 to I. C. Arnold.

Declarations The authors declare no competing interests.

Open Access This article is licensed under a Creative Commons Attribution 4.0 International License, which permits use, sharing, adaptation, distribution and reproduction in any medium or format, as long as you give appropriate credit to the original author(s) and the source, provide a link to the Creative Commons licence, and indicate if changes were made. The images or other third party material in this article are included in the article's Creative Commons licence, unless indicated otherwise in a credit line to the material. If material is not included in the article's Creative Commons licence and your intended use is not permitted by statutory regulation or exceeds the permitted use, you will need to obtain permission directly from the copyright holder. To view a copy of this licence, visit http://creativecommons.org/licenses/by/4.0/.

\section{References}

1. Farahi N, Singh NR, Heard S, Loutsios C, Summers C, Solanki CK, Solanki K, Balan KK, Ruparelia P, Peters AM, Condliffe AM, Chilvers ER (2012) Use of 111-Indium-labeled autologous eosinophils to establish the in vivo kinetics of human eosinophils in healthy subjects. Blood 120(19):4068-4071

2. Mishra A, Hogan SP, Lee JJ, Foster PS, Rothenberg ME (1999) Fundamental signals that regulate eosinophil homing to the gastrointestinal tract. J Clin Invest 103(12):1719-1727

3. Carlens J, Wahl B, Ballmaier M, Bulfone-Paus S, Förster R, Pabst O (2009) Common gamma-chain-dependent signals confer selective survival of eosinophils in the murine small intestine. J Immunol 183(9):5600-5607

4. Shah K, Ignacio A, McCoy KD, Harris NL (2020) The emerging roles of eosinophils in mucosal homeostasis. Mucosal Immunol 13(4):574-583

5. Jung Y, Rothenberg ME (2014) Roles and regulation of gastrointestinal eosinophils in immunity and disease. J Immunol 193(3): 999-1005

6. Lee JJ, Dimina D, Macias MP, Ochkur SI, McGarry M, O'Neill KR, Protheroe C, Pero R, Nguyen T, Cormier SA, Lenkiewicz E, Colbert D, Rinaldi L, Ackerman SJ, Irvin CG, Lee NA (2004) 
Defining a link with asthma in mice congenitally deficient in eosinophils. Science 305(5691):1773-1776

7. Humbles AA, Lloyd CM, McMillan S, Friend DS, Xanthou G, McKenna E, Ghiran S, Gerard NP, Yu C, Orkin SH, Gerard C (2004) A critical role for eosinophils in allergic airways remodeling. Science 305(5691):1776-1779

8. Jenerowicz D, Czarnecka-Operacz M, Silny W (2007) Peripheral blood eosinophilia in atopic dermatitis. Acta Dermatovenerol Alp Pannonica Adriat 16(2):47-52

9. Colombel JF, Torpier G, Janin A, Klein O, Cortot A, Capron M (1992) Activated eosinophils in adult coeliac disease: evidence for a local release of major basic protein. Gut 33(9):1190-1194

10. Hogan SP et al (2008) Eosinophils: biological properties and role in health and disease. Clin Exp Allergy 38(5):709-750

11. DeBrosse CW, Rothenberg ME (2008) Allergy and eosinophilassociated gastrointestinal disorders (EGID). Curr Opin Immunol 20(6):703-708

12. Rosenberg HF, Dyer KD, Foster PS (2013) Eosinophils: changing perspectives in health and disease. Nat Rev Immunol 13(1):9-22

13. Dombrowicz D, Capron M (2001) Eosinophils, allergy and parasites. Curr Opin Immunol 13(6):716-720

14. Van Hulst $\mathrm{G}$ et al (2020) Eosinophil diversity in asthma. Biochem Pharmacol 179:113963

15. Jung Y, Wen T, Mingler MK, Caldwell JM, Wang YH, Chaplin DD, Lee EH, Jang MH, Woo SY, Seoh JY, Miyasaka M, Rothenberg ME (2015) IL-1beta in eosinophil-mediated small intestinal homeostasis and IgA production. Mucosal Immunol 8:930 942

16. Sugawara R, Lee EJ, Jang MS, Jeun EJ, Hong CP, Kim JH, Park A, Yun CH, Hong SW, Kim YM, Seoh JY, Jung YJ, Surh CD, Miyasaka M, Yang BG, Jang MH (2016) Small intestinal eosinophils regulate Th17 cells by producing IL-1 receptor antagonist. J Exp Med 213(4):555-567

17. Arnold IC, Artola-Borán M, Tallón de Lara P, Kyburz A, Taube C, Ottemann K, van den Broek M, Yousefi S, Simon HU, Müller A (2018) Eosinophils suppress Th1 responses and restrict bacterially induced gastrointestinal inflammation. J Exp Med 215(8):20552072

18. Strandmark J, Steinfelder S, Berek C, Kühl AA, Rausch S, Hartmann S (2017) Eosinophils are required to suppress Th2 responses in Peyer's patches during intestinal infection by nematodes. Mucosal Immunol 10(3):661-672

19. Chu DK, Jimenez-Saiz R, Verschoor CP, Walker TD, Goncharova S, Llop-Guevara A, Shen P, Gordon ME, Barra NG, Bassett JD, Kong J, Fattouh R, McCoy KD, Bowdish DM, Erjefält JS, Pabst O, Humbles AA, Kolbeck R, Waserman S, Jordana M (2014) Indigenous enteric eosinophils control DCs to initiate a primary Th2 immune response in vivo. J Exp Med 211(8):1657-1672

20. Chu VT, Beller A, Rausch S, Strandmark J, Zänker M, Arbach O, Kruglov A, Berek C (2014) Eosinophils promote generation and maintenance of immunoglobulin-A-expressing plasma cells and contribute to gut immune homeostasis. Immunity 40(4):582-593

21. Chen HH, Sun AH, Ojcius DM, Hu WL, Ge YM, Lin X', Li LJ, Pan JP, Yan J (2015) Eosinophils from murine lamina propria induce differentiation of naive $\mathrm{T}$ cells into regulatory $\mathrm{T}$ cells via TGFbeta1 and retinoic acid. PLoS One 10(11):e0142881

22. Sefik E, Geva-Zatorsky N, Oh S, Konnikova L, Zemmour D, McGuire AM, Burzyn D, Ortiz-Lopez A, Lobera M, Yang J, Ghosh S, Earl A, Snapper SB, Jupp R, Kasper D, Mathis D, Benoist C (2015) MUCOSAL IMMUNOLOGY. Individual intestinal symbionts induce a distinct population of RORgamma(+) regulatory T cells. Science 349(6251):993-997

23. Ohnmacht C, Park JH, Cording S, Wing JB, Atarashi K, Obata Y, Gaboriau-Routhiau V, Marques R, Dulauroy S, Fedoseeva M, Busslinger M, Cerf-Bensussan N, Boneca IG, Voehringer D, Hase K, Honda K, Sakaguchi S, Eberl G (2015) MUCOSAL
IMMUNOLOGY. The microbiota regulates type 2 immunity through RORgammat(+) T cells. Science 349(6251):989-993

24. Yang BH, Hagemann S, Mamareli P, Lauer U, Hoffmann U, Beckstette M, Föhse L, Prinz I, Pezoldt J, Suerbaum S, Sparwasser T, Hamann A, Floess S, Huehn J, Lochner M (2016) Foxp3(+) T cells expressing RORgammat represent a stable regulatory T-cell effector lineage with enhanced suppressive capacity during intestinal inflammation. Mucosal Immunol 9(2):444-457

25. Kvarnhammar AM, Cardell LO (2012) Pattern-recognition receptors in human eosinophils. Immunology 136(1):11-20

26. Wong CK, Cheung PFY, Ip WK, Lam CWK (2007) Intracellular signaling mechanisms regulating toll-like receptor-mediated activation of eosinophils. Am J Respir Cell Mol Biol 37(1):85-96

27. Driss V, Legrand F, Hermann E, Loiseau S, Guerardel Y, Kremer L, Adam E, Woerly G, Dombrowicz D, Capron M (2009) TLR2dependent eosinophil interactions with mycobacteria: role of alphadefensins. Blood 113(14):3235-3244

28. Takanaski S, Nonaka R, Xing Z, O'Byrne P, Dolovich J, Jordana M (1994) Interleukin 10 inhibits lipopolysaccharide-induced survival and cytokine production by human peripheral blood eosinophils. J Exp Med 180(2):711-715

29. Plotz SG et al (2001) The interaction of human peripheral blood eosinophils with bacterial lipopolysaccharide is CD14 dependent. Blood 97(1):235-241

30. Ivashkiv LB (2018) IFNgamma: signalling, epigenetics and roles in immunity, metabolism, disease and cancer immunotherapy. Nat Rev Immunol 18(9):545-558

31. Murray PJ, Allen JE, Biswas SK, Fisher EA, Gilroy DW, Goerdt S, Gordon S, Hamilton JA, Ivashkiv LB, Lawrence T, Locati M, Mantovani A, Martinez FO, Mege JL, Mosser DM, Natoli G, Saeij JP, Schultze JL, Shirey KA, Sica A, Suttles J, Udalova I, van Ginderachter JA, Vogel SN, Wynn TA (2014) Macrophage activation and polarization: nomenclature and experimental guidelines. Immunity 41(1):14-20

32. Goldszmid RS, Caspar P, Rivollier A, White S, Dzutsev A, Hieny S, Kelsall B, Trinchieri G, Sher A (2012) NK cell-derived interferon-gamma orchestrates cellular dynamics and the differentiation of monocytes into dendritic cells at the site of infection. Immunity 36(6):1047-1059

33. Ellis TN, Beaman BL (2004) Interferon-gamma activation of polymorphonuclear neutrophil function. Immunology 112(1):2-12

34. Yamaguchi T, Kimura H, Kurabayashi M, Kozawa K, Kato M (2008) Interferon-gamma enhances human eosinophil effector functions induced by granulocyte-macrophage colony-stimulating factor or interleukin-5. Immunol Lett 118(1):88-95

35. Griffiths GM (1996) Secretory lysosomes - a special mechanism of regulated secretion in haemopoietic cells. Trends Cell Biol 6(9): 329-332

36. Mahmudi-Azer S, Downey GP, Moqbel R (2002) Translocation of the tetraspanin CD63 in association with human eosinophil mediator release. Blood 99(11):4039-4047

37. Lacy P, Mahmudi-Azer S, Bablitz B, Hagen SC, Velazquez JR, Man SFP, Moqbel R (1999) Rapid mobilization of intracellularly stored RANTES in response to interferon-gamma in human eosinophils. Blood 94(1):23-32

38. Ueki S, Melo RCN, Ghiran I, Spencer LA, Dvorak AM, Weller PF (2013) Eosinophil extracellular DNA trap cell death mediates lytic release of free secretion-competent eosinophil granules in humans. Blood 121(11):2074-2083

39. Daneshpouy M, Socie G, Lemann M, Rivet J, Gluckman E, Janin A (2002) Activated eosinophils in upper gastrointestinal tract of patients with graft-versus-host disease. Blood 99(8):3033-3040

40. Aceves SS, Newbury RO, Dohil R, Bastian JF, Broide DH (2007) Esophageal remodeling in pediatric eosinophilic esophagitis. J Allergy Clin Immunol 119(1):206-212 
41. Tajirian A, Ross R, Zeikus P, Robinson-Bostom L (2007) Subcutaneous fat necrosis of the newborn with eosinophilic granules. J Cutan Pathol 34(7):588-590

42. Neves JS, Perez SAC, Spencer LA, Melo RCN, Reynolds L, Ghiran I, Mahmudi-Azer S, Odemuyiwa SO, Dvorak AM, Moqbel R, Weller PF (2008) Eosinophil granules function extracellularly as receptor-mediated secretory organelles. Proc Natl Acad Sci U S A 105(47):18478-18483

43. Neves JS, Radke AL, Weller PF (2010) Cysteinyl leukotrienes acting via granule membrane-expressed receptors elicit secretion from within cell-free human eosinophil granules. J Allergy Clin Immunol 125(2):477-482

44. Watanabe Y, Hamaguchi-Tsuru E, Morimoto N, Nishio Y, Yagyu KI, Konishi Y, Tominaga M, Miyazaki JI, Furuya M, Tominaga A (2004) IL-5-induced eosinophils suppress the growth of leishmania amazonensis in vivo and kill promastigotes in vitro in response to either IL-4 or IFN-gamma. DNA Cell Biol 23(7):412-418

45. Yousefi S, Gold JA, Andina N, Lee JJ, Kelly AM, Kozlowski E, Schmid I, Straumann A, Reichenbach J, Gleich GJ, Simon HU (2008) Catapult-like release of mitochondrial DNA by eosinophils contributes to antibacterial defense. Nat Med 14(9):949-953

46. Mazmanian SK, Liu CH, Tzianabos AO, Kasper DL (2005) An immunomodulatory molecule of symbiotic bacteria directs maturation of the host immune system. Cell 122(1):107-118

47. Reichman H, Itan M, Rozenberg P, Yarmolovski T, Brazowski E, Varol C, Gluck N, Shapira S, Arber N, Qimron U, Karo-Atar D, Lee JJ, Munitz A (2019) Activated eosinophils exert antitumorigenic activities in colorectal cancer. Cancer Immunol Res 7(3):388-400

48. Griseri T, McKenzie BS, Schiering C, Powrie F (2012) Dysregulated hematopoietic stem and progenitor cell activity promotes interleukin-23-driven chronic intestinal inflammation. Immunity 37(6):1116-1129

49. Baldridge MT, King KY, Boles NC, Weksberg DC, Goodell MA (2010) Quiescent haematopoietic stem cells are activated by IFNgamma in response to chronic infection. Nature 465(7299):793797

50. Griseri T, Arnold IC, Pearson C, Krausgruber T, Schiering C, Franchini F, Schulthess J, McKenzie BS, Crocker PR, Powrie F (2015) Granulocyte macrophage colony-stimulating factor-activated eosinophils promote interleukin-23 driven chronic colitis. Immunity 43(1):187-199

51. Ahrens R, Waddell A, Seidu L, Blanchard C, Carey R, Forbes E, Lampinen M, Wilson T, Cohen E, Stringer K, Ballard E, Munitz A, Xu H, Lee N, Lee JJ, Rothenberg ME, Denson L, Hogan SP (2008) Intestinal macrophage/epithelial cell-derived CCL11/eotaxin-1 mediates eosinophil recruitment and function in pediatric ulcerative colitis. J Immunol 181(10):7390-7399

52. Loktionov A (2019) Eosinophils in the gastrointestinal tract and their role in the pathogenesis of major colorectal disorders. World J Gastroenterol 25(27):3503-3526

53. Saitoh O, Kojima K, Sugi K, Matsuse R, Uchida K, Tabata K, Nakagawa K, Kayazawa M, Hirata I, Katsu KI (1999) Fecal eosinophil granule-derived proteins reflect disease activity in inflammatory bowel disease. Am J Gastroenterol 94(12):3513-3520

54. Raab Y, Fredens K, Gerdin B, Hallgren R (1998) Eosinophil activation in ulcerative colitis: studies on mucosal release and localization of eosinophil granule constituents. Dig Dis Sci 43(5):10611070

55. Jeziorska M, Haboubi N, Schofield P, Woolley DE (2001) Distribution and activation of eosinophils in inflammatory bowel disease using an improved immunohistochemical technique. J Pathol 194(4):484-492

56. Coppi LC, Thomazzi SM, Ayrizono MLS, Coy CSR, Fagundes JJ, Goes JRN, Franchi GC Jr, Nowill AE, Montes CG, Antunes E, Ferraz JGP (2007) Comparative study of eosinophil chemotaxis, adhesion, and degranulation in vitro in ulcerative colitis and Crohn's disease. Inflamm Bowel Dis 13(2):211-218

57. Lampinen M, Rönnblom A, Amin K, Kristjansson G, Rorsman F, Sangfelt P, Säfsten B, Wagner M, Wanders A, Winqvist O, Carlson $M$ (2005) Eosinophil granulocytes are activated during the remission phase of ulcerative colitis. Gut 54(12):1714-1720

58. Masterson JC, McNamee EN, Fillon SA, Hosford L, Harris R, Fernando SD, Jedlicka P, Iwamoto R, Jacobsen E, Protheroe C, Eltzschig HK, Colgan SP, Arita M, Lee JJ, Furuta GT (2015) Eosinophil-mediated signalling attenuates inflammatory responses in experimental colitis. Gut 64(8):1236-1247

59. Forbes E, Murase T, Yang M, Matthaei KI, Lee JJ, Lee NA, Foster PS, Hogan SP (2004) Immunopathogenesis of experimental ulcerative colitis is mediated by eosinophil peroxidase. J Immunol 172(9):5664-5675

60. Linch SN, Kelly AM, Danielson ET, Pero R, Lee JJ, Gold JA (2009) Mouse eosinophils possess potent antibacterial properties in vivo. Infect Immun 77(11):4976-4982

61. Gigon L, Yousefi S, Karaulov A, Simon HU (2021) Mechanisms of toxicity mediated by neutrophil and eosinophil granule proteins. Allergol Int 70(1):30-38

62. Rosenberg HF (1995) Recombinant human eosinophil cationic protein. Ribonuclease activity is not essential for cytotoxicity. J Biol Chem 270(14):7876-7881

63. Karawajczyk M et al (1995) The differential release of eosinophil granule proteins. Studies on patients with acute bacterial and viral infections. Clin Exp Allergy 25(8):713-719

64. Bystrom J, Amin K, Bishop-Bailey D (2011) Analysing the eosinophil cationic protein-a clue to the function of the eosinophil granulocyte. Respir Res 12:10

65. Torrent M, Cuyás E, Carreras E, Navarro S, López O, de la Maza A, Nogués MV, Reshetnyak YK, Boix E (2007) Topography studies on the membrane interaction mechanism of the eosinophil cationic protein. Biochemistry 46(3):720-733

66. Torrent M, Sánchez D, Buzón V, Nogués MV, Cladera J, Boix E (2009) Comparison of the membrane interaction mechanism of two antimicrobial RNases: RNase 3/ECP and RNase 7. Biochim Biophys Acta 1788(5):1116-1125

67. Lehrer RI et al (1989) Antibacterial properties of eosinophil major basic protein and eosinophil cationic protein. J Immunol 142(12): $4428-4434$

68. Torrent M, Navarro S, Moussaoui M, Nogués MV, Boix E (2008) Eosinophil cationic protein high-affinity binding to bacteria-wall lipopolysaccharides and peptidoglycans. Biochemistry 47(11): 3544-3555

69. Torrent M, Odorizzi F, Nogués MV, Boix E (2010) Eosinophil cationic protein aggregation: identification of an $\mathrm{N}$-terminus amyloid prone region. Biomacromolecules 11(8):1983-1990

70. Abu-Ghazaleh RI, Gleich GJ, Prendergast FG (1992) Interaction of eosinophil granule major basic protein with synthetic lipid bilayers: a mechanism for toxicity. J Membr Biol 128(2):153-164

71. Soragni A, Yousefi S, Stoeckle C, Soriaga AB, Sawaya MR, Kozlowski E, Schmid I, Radonjic-Hoesli S, Boutet S, Williams GJ, Messerschmidt M, Seibert MM, Cascio D, Zatsepin NA, Burghammer M, Riekel C, Colletier JP, Riek R, Eisenberg DS, Simon HU (2015) Toxicity of eosinophil MBP is repressed by intracellular crystallization and promoted by extracellular aggregation. Mol Cell 57(6):1011-1021

72. Kita $\mathrm{H}$ et al (1995) Eosinophil major basic protein induces degranulation and IL-8 production by human eosinophils. J Immunol 154(9):4749-4758

73. Ten RM et al (1989) Molecular cloning of the human eosinophil peroxidase. Evidence for the existence of a peroxidase multigene family. J Exp Med 169(5):1757-1769 
74. Persson T, Andersson P, Bodelsson M, Laurell M, Malm J, Egesten A (2001) Bactericidal activity of human eosinophilic granulocytes against Escherichia coli. Infect Immun 69(6):3591-3596

75. Borelli V, Vita F, Shankar S, Soranzo MR, Banfi E, Scialino G, Brochetta C, Zabucchi G (2003) Human eosinophil peroxidase induces surface alteration, killing, and lysis of Mycobacterium tuberculosis. Infect Immun 71(2):605-613

76. Dworski R, Simon HU, Hoskins A, Yousefi S (2011) Eosinophil and neutrophil extracellular DNA traps in human allergic asthmatic airways. J Allergy Clin Immunol 127(5):1260-1266

77. Simon D, Hoesli S, Roth N, Staedler S, Yousefi S, Simon HU (2011) Eosinophil extracellular DNA traps in skin diseases. J Allergy Clin Immunol 127(1):194-199

78. Simon D, Radonjic-Hösli S, Straumann A, Yousefi S, Simon HU (2015) Active eosinophilic esophagitis is characterized by epithelial barrier defects and eosinophil extracellular trap formation. Allergy 70(4):443-452

79. Gevaert E, Zhang N, Krysko O, Lan F, Holtappels G, de Ruyck N, Nauwynck H, Yousefi S, Simon HU, Bachert C (2017) Extracellular eosinophilic traps in association with Staphylococcus aureus at the site of epithelial barrier defects in patients with severe airway inflammation. J Allergy Clin Immunol 139(6):1849-1860 e6

80. Simon HU, Yousefi S, Germic N, Arnold IC, Haczku A, Karaulov AV, Simon D, Rosenberg HF (2020) The cellular functions of eosinophils: Collegium Internationale Allergologicum (CIA) Update 2020. Int Arch Allergy Immunol 181(1):11-23

81. Mukherjee M, Lacy P, Ueki S (2018) Eosinophil extracellular traps and inflammatory pathologies-untangling the Web! Front Immunol 9:2763

82. Germic $\mathrm{N}$ et al (2021) The release kinetics of eosinophil peroxidase and mitochondrial DNA is different in association with eosinophil extracellular trap formation. Cells 10(2)

83. Prince LR, Graham KJ, Connolly J, Anwar S, Ridley R, Sabroe I, Foster SJ, Whyte MKB (2012) Staphylococcus aureus induces eosinophil cell death mediated by alpha-hemolysin. PLoS One 7(2): e31506

84. Lina TT, Alzahrani S, Gonzalez J, Pinchuk IV, Beswick EJ, Reyes VE (2014) Immune evasion strategies used by Helicobacter pylori. World J Gastroenterol 20(36):12753-12766

85. Carding S et al (2015) Dysbiosis of the gut microbiota in disease. Microb Ecol Health Dis 26:26191

86. Nishida A, Inoue R, Inatomi O, Bamba S, Naito Y, Andoh A (2018) Gut microbiota in the pathogenesis of inflammatory bowel disease. Clin J Gastroenterol 11(1):1-10

87. Bunker JJ, Bendelac A (2018) IgA responses to microbiota. Immunity 49(2):211-224

88. Catanzaro JR, Strauss JD, Bielecka A, Porto AF, Lobo FM, Urban A, Schofield WB, Palm NW (2019) IgA-deficient humans exhibit gut microbiota dysbiosis despite secretion of compensatory IgM. Sci Rep 9(1):13574

89. Suzuki K, Meek B, Doi Y, Muramatsu M, Chiba T, Honjo T, Fagarasan S (2004) Aberrant expansion of segmented filamentous bacteria in IgA-deficient gut. Proc Natl Acad Sci U S A 101(7): 1981-1986

90. Yu C, Cantor AB, Yang H, Browne C, Wells RA, Fujiwara Y, Orkin SH (2002) Targeted deletion of a high-affinity GATA-binding site in the GATA-1 promoter leads to selective loss of the eosinophil lineage in vivo. J Exp Med 195(11):1387-1395

91. Forman R, Bramhall M, Logunova L, Svensson-Frej M, Cruickshank SM, Else KJ (2016) Eosinophils may play regionally disparate roles in influencing $\operatorname{IgA}(+)$ plasma cell numbers during large and small intestinal inflammation. BMC Immunol 17(1):12

92. Singh G, Brass A, Knight CG, Cruickshank SM (2019) Gut eosinophils and their impact on the mucus-resident microbiota. Immunology 158(3):194-205

93. Beller A, Kruglov A, Durek P, Goetze V, Werner K, Heinz GA, Ninnemann J, Lehmann K, Maier R, Hoffmann U, Riedel R, Heiking K, Zimmermann J, Siegmund B, Mashreghi MF, Radbruch A, Chang HD (2020) Specific microbiota enhances intestinal IgA levels by inducing TGF-beta in T follicular helper cells of Peyer's patches in mice. Eur J Immunol 50(6):783-794

94. Buonomo EL, Cowardin CA, Wilson MG, Saleh MM, Pramoonjago P, Petri WA Jr (2016) Microbiota-regulated IL-25 increases eosinophil number to provide protection during Clostridium difficile infection. Cell Rep 16(2):432-443

95. Frank DN, St. Amand AL, Feldman RA, Boedeker EC, Harpaz N, Pace NR (2007) Molecular-phylogenetic characterization of microbial community imbalances in human inflammatory bowel diseases. Proc Natl Acad Sci U S A 104(34):13780-13785

96. Maslowski KM, Vieira AT, Ng A, Kranich J, Sierro F, di Yu, Schilter HC, Rolph MS, Mackay F, Artis D, Xavier RJ, Teixeira MM, Mackay CR (2009) Regulation of inflammatory responses by gut microbiota and chemoattractant receptor GPR43. Nature 461(7268):1282-1286

97. Theiler A, Bärnthaler T, Platzer W, Richtig G, Peinhaupt M, Rittchen S, Kargl J, Ulven T, Marsh LM, Marsche G, Schuligoi R, Sturm EM, Heinemann A (2019) Butyrate ameliorates allergic airway inflammation by limiting eosinophil trafficking and survival. J Allergy Clin Immunol 144(3):764-776

98. Jimenez-Saiz R et al (2020) Microbial regulation of enteric eosinophils and its impact on tissue remodeling and Th2 immunity. Front Immunol 11:155

Publisher's note Springer Nature remains neutral with regard to jurisdictional claims in published maps and institutional affiliations. 